\title{
RELAÇÕES ESTABELECIDAS PELAS ENFERMEIRAS COM A FAMÍLIA DURANTE A HOSPITALIZAÇÃO INFANTIL
}

\author{
Aline Soares de Lima1, Vivian Karla Bezerra Alves da Silva², Neusa Collet', Altamira Pereira da Silva \\ Reichert ${ }^{4}$, Beatriz Rosana Gonçalves de Oliveira ${ }^{5}$
}

${ }^{1}$ Mestranda do Programa de Pós-Graduação em Enfermagem da Universidade Federal da Bahia. Bolsista da Fundação de Amparo à Pesquisa do Estado da Bahia. Bahia, Brasil. E-mail: alinelimajp@hotmail.com

${ }^{2}$ Enfermeira. Residente de Saúde da Família e Comunidade do Núcleo de Estudos em Saúde Coletiva da Universidade Federal da Paraíba (UFPB). Paraíba, Brasil. E-mail: viviannutreira@hotmail.com

${ }^{3}$ Doutora em Enfermagem. Docente do Curso de Graduação em Enfermagem e do Programa de Pós-Graduação em Enfermagem da UFPB. Paraíba, Brasil. E-mail: neucollet@gmail.com

${ }^{4}$ Doutoranda do Programa de Pós-Graduação em Saúde da Criança e do Adolescente da Universidade Federal de Pernambuco. Docente do Curso de Graduação em Enfermagem da UFPB. Paraíba, Brasil. E-mail: altreichert@uol.com.br

${ }^{5}$ Doutoranda do Programa de Pós-Graduação em Enfermagem em Saúde Pública da Escola de Enfermagem de Ribeirão Preto da Universidade de São Paulo. Docente do Curso de Graduação em Enfermagem da Universidade Estadual do Oeste do Paraná. Paraná, Brasil. E-mail: lb.toso@certto.com.br

RESUMO: Estudo qualitativo que objetivou analisar as relações que as enfermeiras estabelecem com a família durante o período de hospitalização de seus filhos e verificar como tem sido a participação da família nos cuidados à criança hospitalizada. Os dados empíricos foram coletados por meio da observação participante e da entrevista semi-estruturada. A interpretação dos dados seguiu os fundamentos da análise temática. Os resultados evidenciam que as relações que as enfermeiras estabelecem com as famílias das crianças hospitalizadas não contemplam as necessidades destas, comprometendo a assistência à díade criança-família. Estas relações são objetivas, sucintas, formais e unilaterais, com predominância da enfermagem. Percebe-se que a família foi inserida na realização dos cuidados à criança, porém tem havido uma delegação de cuidados sem uma coparticipação por parte das enfermeiras, e nem uma negociação dessas ações, remetendo a uma reflexão sobre essas relações de modo que a assistência à díade possa estar balizada pelo princípio da integralidade.

DESCRITORES: Enfermagem pediátrica. Criança hospitalizada. Família. Relações profissional-família.

\section{RELATIONSHIPS ESTABLISHED BY NURSES WITH FAMILIES DURING CHILD HOSPITALIZATION}

\begin{abstract}
This qualitative study aimed to analyze the relationships between nurses and the families during their children's hospitalization and investigate how the family had participated in the care. Empirical data was collected through participant observation and semi-structured interview. The data interpretation was based on foundations of thematic analysis. The results have shown that the relationships between nurses and families during the children's hospitalization have not reached their needs, compromising the assistance to the duo child-family frame. These relationships are objective, concise, formal and unilateral, with nursing predominance. It was noticed that the families were included in the implementation of the child care, although it had been a negligence of care coparticipation by nurses, and even a negotiation of such actions, taking them to reflect on these relationships so that the duo child-family assistance can be reasoned by the principle of integrality.

DESCRIPTORS: Pediatric nursing. Hospitalized child. Family. Professional-family relationships.

\section{RELACIONES ESTABLECIDAS POR LAS ENFERMERAS CON LA FAMILIA DURANTE LA HOSPITALIZACIÓN INFANTIL}

\begin{abstract}
RESUMEN: Estudio cualitativo que tuvo por objetivo analizar las relaciones que las enfermeras establecen con la familia durante el período de hospitalización de sus hijos y examinar cómo la familia participa de los cuidados del niño hospitalizado. Los datos empíricos fueron levantados por medio de la observación participante y de la entrevista semi-estructurada. La interpretación de los datos siguió los fundamentos del análisis temático. Los resultados evidencian que las relaciones que las enfermeras establecen con las familias de los niños hospitalizados no contemplan las necesidades de éstos, comprometiendo la asistencia a la díada niño-familia. Estas relaciones son objetivas, sucintas, formales y unilaterales, con predominio de la enfermería. Se nota que la familia fue inserta en la realización de los cuidados al niño, pero sin embargo se produjo delegación de cuidados sin una coparticipación por parte de las enfermeras, y no hubo una negociación de esas acciones, lo que remite a una reflexión sobre esas relaciones de modo que la asistencia a la díada pueda estar embasada por el principio de la integralidad.
\end{abstract}

DESCRIPTORES: Enfermería pediátrica. Niño hospitalizado. Familia. Relaciones profesional-familia. 


\section{INTRODUÇÃO}

No Brasil, a presença de um acompanhante nas enfermarias pediátricas não era parte integrante da rotina dos serviços de saúde. Isto só passou a ser possível quando, em 13 de junho de 1990, foi promulgada a Lei no 8069 que regulamenta o Estatuto da Criança e do Adolescente (ECA) e discursa, em seu Artigo 12, sobre o direito à permanência dos pais ou responsável, em tempo integral, durante a internação da criança ou adolescente. ${ }^{1}$ Com isso, a permanência dos pais durante a hospitalização do filho tem sido alvo de estudos na enfermagem, contribuindo para reflexões acerca da participação destes nesse processo e de como tem sido a relação da enfermagem com os cuidadores das crianças que foram inseridos no cotidiano do trabalho.

A inserção da família no ambiente hospitalar, considerando-se seus direitos e deveres, tem demandado novas formas de organização na dinâmica da assistência de enfermagem, na qual, além do cuidado integral à criança, torna-se imprescindível também, voltar a atenção às necessidades da família, desenvolvendo, assim, uma proposta de cuidado centrado na díade criançafamília. Isto requer dos profissionais de saúde o atendimento de necessidades não apenas clínicas, mas também emocionais, afetivas e sociais, o que, ao mesmo tempo em que possibilita um cuidado mais abrangente, demanda mudanças nos modos de atender à criança hospitalizada.

Transformações dessa natureza implicam no reconhecimento da família como unidade básica dos cuidados à saúde da criança, estimulando-a a participar como tal, mas percebendo-a e compreendendo-a de modo que suas necessidades também sejam atendidas. ${ }^{2}$ É nessa perspectiva que a família passa a ser envolvida no cuidado e a ser cuidada, fazendo parte do conjunto da assistência em pediatria. ${ }^{3}$

No entanto, no cotidiano do trabalho no hospital, a convivência entre família e profissionais de enfermagem tem evidenciado a presença de conflitos que vêm sendo desencadeados, em grande parte, pelo despreparo desses em lidar com a dor e o sofrimento da criança e sua família. Além disso, a literatura aponta dificuldades dos profissionais em estabelecer efetivo processo de comunicação com a família, ${ }^{4}$ podendo comprometer a assistência, visto que o cuidado à criança não pode estar desvinculado do cuidado à família.

Apesar dos conflitos existentes, a família tem participado do processo de cuidado à criança, contudo, as condições de experienciação do cui- dado compartilhado entre enfermagem e família não têm sido discutidas. ${ }^{5} \mathrm{O}$ cuidado, que antes era prestado apenas pela equipe de enfermagem, tem sido compartilhado com a família ou, muitas vezes, delegado a esta, caracterizando um processo de desresponsabilização da equipe com cuidados que, às vezes, são menos valorizados pela enfermagem, como o banho, a alimentação e o conforto, ${ }^{6}$ evidenciando uma divisão de tarefas pautada no saber científico, operado pela enfermagem, e no saber popular, operado pela família.

Compreendemos que o Alojamento Conjunto Pediátrico (ACP) deva se constituir como espaço de construção e partilha de conhecimentos que possam se traduzir em satisfação das necessidades da díade criança-família. Assim, para que a família não seja unicamente executora de ações de cuidado, é fundamental seu envolvimento na assistência, oferecendo-lhe condições de participação no processo terapêutico como um todo, respeitando seus limites emocionais e habilidades em prestar os cuidados ao filho durante seu período de hospitalização. Além disso, é importante também o estabelecimento de relações de empatia e intersubjetividade entre a enfermagem e a família, facilitando a participação desta nas ações de cuidado. $^{7}$

Nesse sentido, consideramos importante refletir acerca das relações que os profissionais da enfermagem, especificamente as enfermeiras, por sua condição de responsáveis por uma equipe que desenvolve o cuidado, têm estabelecido com as famílias durante o período de hospitalização infantil, além de sua participação nos cuidados. Destacamos a importância do estudo para a melhoria do cuidado à criança e sua família, pois as reflexões sobre esta temática poderão trazer contribuições para que a assistência prestada possa ser balizada pelo princípio da integralidade. Sendo assim, tivemos como objetivo analisar as relações que as enfermeiras estabelecem com a família durante o período de hospitalização de seus filhos e verificar como tem sido a participação da família nos cuidados à criança hospitalizada.

\section{METODOLOGIA}

Trata-se de uma pesquisa com abordagem qualitativa do tipo descritivo-exploratória. A pesquisa de campo foi realizada no período de março a junho de 2007, na unidade de internação pediátrica de um hospital universitário na cidade de João Pessoa-Paraíba, instituição pública federal referência para tratamento de doenças crônicas e raras. 
Os critérios de inclusão dos sujeitos na pesquisa foram: ser enfermeira e atuar na unidade em estudo há mais de um ano. No período da coleta dos dados trabalhavam na referida unidade 10 enfermeiras, todas do sexo feminino. Destas, seis atenderam aos critérios de inclusão e participaram do estudo.

A coleta de dados empíricos foi efetuada por meio de observação participante e de entrevista semi-estruturada. Optamos pela observação participante visto que essa técnica facilita o rápido acesso aos dados sobre as situações do cotidiano de trabalho em que os sujeitos se encontram envolvidos, bem como a captação de palavras e esclarecimentos que acompanham o comportamento dos observados. ${ }^{8}$ Os registros da observação foram anotados em diário de campo, contemplando duas partes, uma descritiva e outra reflexiva. A observação foi centrada na enfermeira (unidade de observação), sendo realizada individualmente, participando-se conjuntamente de suas atividades. $\mathrm{O}$ roteiro privilegiou a identificação de como as enfermeiras estabeleciam relações com a família da criança hospitalizada. Adotamos um posicionamento móvel, com acompanhamento e registro de movimentos, falas, ações, expressões, espaço físico e de relações. A entrevista semi-estruturada foi utilizada como técnica complementar à observação participante, com vistas a aprofundar e/ou esclarecer aspectos relevantes, mas que não foram apreendidos durante a observação. As questões norteadoras da entrevista foram: Como tem sido sua relação com a família da criança durante a hospitalização? Como é sua comunicação com a família? As entrevistas foram gravadas em MP3 player, após anuência das enfermeiras e, posteriormente, transcritas na íntegra.

A análise dos dados empíricos seguiu os princípios da análise temática9 e a operacionalização deu-se pelos seguintes passos: a) ordenação dos dados; b) classificação; e c) análise final. ${ }^{9}$ Após a transcrição das entrevistas, realizamos leitura exaustiva e repetida das mesmas, bem como dos registros do diário de campo, fazendo uma relação interrogativa e articulada com eles. Esse procedimento permitiu realizar a ordenação do conjunto dos dados empíricos, iniciando uma primeira classificação para apreender as estruturas de relevância. A partir destas, reagrupamos os temas mais relevantes para proceder à análise final.

Atendendo à Resolução no 196/96 do Ministério da Saúde, a pesquisa foi aprovada pelo Comitê de Ética em Pesquisa do hospital em estudo, sob o Protocolo $n^{\circ}$ 059/06. Todos os sujeitos da pesquisa assinaram o Termo de Consentimento Livre e Esclarecido. No texto, a identificação das observações e entrevistas realizadas foi procedida da seguinte forma: observação $1(\mathrm{O} 1)$, entrevista 1 (E1) e assim sucessivamente.

\section{RESULTADOS E DISCUSSÃO}

A enfermagem se caracteriza como uma profissão produtora de ações de cuidado. Essas devem ser desenvolvidas em conjunto com o ser cuidado, resultando em interação, relação empática, envolvimento, solidariedade, responsabilização e não apenas em procedimentos técnicos. ${ }^{10}$ Em se tratando do ACP, essas ações devem envolver a criança e sua família, pois as necessidades de ambos são produzidas simultaneamente no hospital.

A partir da análise do conjunto do material empírico produzido, foi construída a seguinte categoria empírica: relação entre a enfermeira e a família na hospitalização infantil: interação e produção do cuidado, subdividida em cinco subcategorias, a saber, o início de uma relação de cuidados entre a enfermeira e a díade criança-família; a racionalidade técnica predominando sobre a subjetividade; a presença da família no hospital compreendida como recursos humanos auxiliares; cuidado prestado à criança pelas mães e equipe de enfermagem: relação assimétrica; a percepção dos sentimentos da família na execução de procedimentos técnicos, a serem apresentadas a seguir.

\section{O início de uma relação de cuidados entre a enfermeira e a díade criança-família}

O primeiro contato entre a família e a enfermeira se dá no momento da chegada da família no hospital, na admissão da criança, ocasião na qual são coletados dados sociais e informações acerca do estado geral da criança.

É também neste momento que a gente explica todas as normas do hospital, da clínica em si, porque cada clínica do hospital tem suas normas (E2).

A enfermeira de plantão chamou a mãe pelo nome, informou-lhe sobre o horário das refeições e disse: daqui a pouco você venha aqui para eu the dar os tickets de refeição (O6).

Esse é o momento em que a família é orientada pelas enfermeiras quanto às normas e rotinas do setor, no entanto, é provável que a família pouco assimile as informações recebidas nesse período, devido à existência do estresse viven- 
ciado em relação à doença do filho, pelo processo de hospitalização e por estar em um ambiente desconhecido.

Ao entrar na enfermaria, a enfermeira se dirigiu à criança que havia sido admitida naquela hora. Olhou para a mãe e perguntou se estava tudo em ordem. A mãe respondeu que sim. Olhou novamente a criança e perguntou à mãe se ela já havia estado internada outras vezes. Mais uma vez a mãe confirmou balançando afirmativamente a cabeça. Dirigindo-se à criança, disse: agora ele vai melhorar! Daqui a pouco as meninas [técnicas de enfermagem] vão vir aqui colocar o termômetro e ver a pressão dele. Qualquer coisa me chame (O23).

[...] a gente preenche a folhinha da admissão [...] a gente pergunta o nome completo da mãe, o endereço, porque tem muitas que vêm de outras cidades, e escreve o diagnóstico médico. Aí, depois de ver como ele tá, a gente faz uma evoluçãozinha do estado geral (E5).

Ainda que a maioria dos pais receba informações precárias durante a admissão, percebeu-se que pouco se fala sobre o motivo da internação, o estado de saúde da criança ou o tratamento. Tampouco, abre-se espaço para a família expressar dúvidas ou fazer perguntas. A maioria não é informada sobre seus direitos e deveres durante sua permanência no hospital, nem sobre sua participação nos cuidados ao filho. Esse modo de organizar o trabalho se apresenta como uma lacuna na assistência, pois a informação sobre as normas e rotinas do serviço poderia ser uma das formas de se criar um primeiro vínculo com a criança e a família para, oportunamente, estabelecer uma relação de coparticipação.

Fornecer à família informação completa, apurada, correta e clara a respeito do estado de saúde do filho, do diagnóstico, tratamento e prognóstico, além de verificar o grau de compreensão que a família possui sobre esses processos, é dever da enfermeira, e essa troca de informações significa compartilhamento de cuidado. ${ }^{11}$ Assim, o diálogo se faz importante no cotidiano da assistência de enfermagem à criança e sua família, rompendo barreiras e fortalecendo as relações, ${ }^{12}$ mas não se trata do diálogo que busca junto à família informações sobre a criança para a equipe planejar o cuidado. Implica na produção do diálogo interativo que permite a coparticipação e coresponsabilização da enfermeira e da família pelo cuidado.

Teve uma mãe que chegou e já foi chorando, porque você não tá preparada para ficar dentro de um hospital com criança não, porque não é fácil ficar com uma criança doente, então ela vai ter que ser preparada para isso, muito bem preparada (E1).
As enfermeiras salientam que na prática cotidiana o acompanhante quando chega, não recebe aquele apoio do enfermeiro, do assistente social, do psicólogo, do médico (E4). Embora haja certa preocupação com os sentimentos, a enfermeira não está preparada para acolher os familiares num momento tão difícil como é o da internação hospitalar de uma criança.

O momento da admissão da criança no hospital tem se mostrado crítico para a família, pois, a partir da notícia de que o filho ficará hospitalizado, emergem sentimentos de angústia e incerteza que geram sofrimento. Cabe à enfermeira compreender a vivência de cada família nesse contexto e propor intervenções que a auxiliem a lidar com a situação.

\section{A racionalidade técnica predominando sobre a subjetividade}

Mesmo não promovendo acolhimento das demandas da família no momento da admissão, a enfermeira buscou identificar as necessidades que a família tem, porque a família é muito lesada em todo esse processo, né? (E4). No entanto, não basta identificar as demandas de cuidado, é preciso por em prática um plano de trabalho cotidiano que considere a família como objeto de ação, pois se percebe que no decorrer do período de internação, as necessidades e problemas da família têm sido, em diversos momentos, esquecidos, ou tido atenção secundária.

A enfermeira se aproximou para observar a sonda enteral e perguntou à mãe se a criança havia dormido bem à noite. A mãe respondeu que sim, mas que ela mesma não havia dormido, pois passara a noite toda sentada em uma cadeira desconfortável ao lado da filha e reclamou de dores nas costas. A enfermeira disse que era assim mesmo e saiu da enfermaria $(\mathrm{O} 3)$.

Atitudes dessa natureza no cotidiano de trabalho das enfermeiras demonstram que a família não tem sido acolhida pelas profissionais, entendendo aqui o acolhimento como sendo o ato de atender aqueles que se encontram nos serviços de saúde, ouvindo seus pedidos e assumindo uma postura capaz de dar respostas adequadas às necessidades dos usuários. ${ }^{13}$

É reconhecida também a importância de se promover aproximação e vínculo com a família, pois a hospitalização se constitui como uma situação difícil para a família da criança hospitalizada. Isto ocorre gradativamente por meio do diálogo e do respeito. [...] a gente tenta manter a relação com elas 
[mães] dessa forma de tá chegando perto, de tá respeitando também o conhecimento que elas têm com relação aos cuidados que elas têm em casa, às vezes são mães que têm medo e a gente tenta conversar com ela, fazer com que ela fique mais próxima da criança. Assim, a gente tem tentado manter essa relação dessa forma (E3).

Entretanto, a prática cotidiana revela outra dimensão: [...] a enfermeira se dirigiu à enfermaria a fim de fazer o curativo de uma ferida cirúrgica de uma menina de seis anos. Aproximou-se da menina, conversou com ela, dizendo que iria retirar aquele curativo sujo e fazer um novo. Durante a realização do mesmo procurou manter uma conversa com a criança no intuito de distraí-la. A mãe, sentada em uma cadeira ao lado do leito, observava atentamente, em silêncio, o procedimento. Terminado o procedimento, a enfermeira recolheu o material e saiu da enfermaria, sem, no entanto, explicar a evolução da ferida à mãe $(\mathrm{O} 4)$.

A falta de informação coerente e precisa é um dos aspectos que mais preocupa e provoca ansiedade nos pais, além de limitar a participação destes no cuidado à criança hospitalizada. Fatores, estes, estressantes, e que geram preocupações, podendo ser evitados ou minimizados diante de uma explicação, por parte da enfermeira, sobre os procedimentos feitos e os benefícios ocasionados por estes, estabelecendo-se um encontro de cuidado no qual a interação seria realizada plenamente por meio de um diálogo esclarecedor com a família e com a criança, buscando o sentido e o significado dessas ações em saúde.

A mãe se dirigiu ao posto de enfermagem pedindo a medicação [Rivotril ${ }^{\circledR}$ ] da filha. A enfermeira disse-lhe que estava faltando e que já havia pedido à farmácia. A mãe falou: "pronto! Minha menina tá agoniada demais, tá com soluço, o que eu faço?" Logo veio a resposta: "não se aperreie, não! Não tem que fazer nada não! É só esperar o soluço passar" (O8).

Encontros de cuidado dessa natureza inviabilizam a interação entre enfermeiras e mães, propiciando tão somente o cumprimento mecânico de tarefas em uma lógica de relação não terapêutica nem resolutiva. Ao negar a ação em saúde, nesse caso, a falta do medicamento, a relação não se estabelece e enfraquece, pois o agente que deveria solucionar os problemas, naquela situação, está se abstendo de sua responsabilidade quando afirma claramente que a angústia da mãe não é procedente, e a orienta para que tenha controle emocional, como se esse comportamento fosse possível e natural frente à hospitalização infantil.

A enfermeira adentrou à enfermaria e perguntou à mãe se a criança havia tido febre durante a noite. A mãe respondeu que não. Tornou a perguntar: "mãe, ela já fez xixi?" A mãe balançou a cabeça, afirmando (O1).

A enfermeira não interage com a mãe, limitando-se a fazer perguntas curtas relacionadas ao estado geral da criança. Há uma despersonalização do cuidado evidenciado pelo modo como as enfermeiras se dirigem às mães. Autores afirmam que este tipo de interação insatisfatória entre os agentes de saúde (neste caso, a enfermeira) e os usuários trata-se de uma relação assimétrica de cuidado. ${ }^{14,15}$ Assim, não existe espaço de escuta no encontro do cuidado, tampouco de acolhimento às demandas da família. Esse encontro tem se limitado à tarefa de colher informações.

Nesse sentido, entre profissional de saúde e usuário, a comunicação, a troca, é desigual, e o profissional tem a prerrogativa hierárquica de conduzir o relato do doente, interferindo com outras perguntas ou mesmo interrompendo-o, o que nos faz lembrar que as interações entre os atores (profissionais e pacientes) são influenciadas por lógicas culturais que os antecedem. Assim, para pensar as (im)possibilidades comunicacionais entre os sujeitos na organização hospitalar, é preciso pensar a própria cultura organizacional. ${ }^{16}$

\section{A presença da família no hospital compreen- dida como recursos humanos auxiliares}

Desde a década de 1960, vários estudos têm descrito a participação da família durante a internação hospitalar como fator fundamental de apoio à criança hospitalizada. ${ }^{14}$ Sua importância está no sentido de que não é rompido o vínculo, a criança não se sente sozinha e com pessoas estranhas, diminuindo o custo e o tempo de internação.

Ao reconhecerem a importância da presença das mães no hospital, durante a internação de seu filho, relatou-se que as mães são muito importantes no cuidado à criança, então a enfermagem tem que conquistar as mães (E1). Nesse sentido, a família é vista como mediadora da relação equipe-criança, dando-lhe segurança e conforto, ao mesmo tempo em que facilita o trabalho a ser realizado pela enfermagem.

[...] facilita a aproximação da equipe, porque tem a família como mediadora. Quando você vai realizar um procedimento doloroso, a família estando perto, é uma segurança que ela dá, deixa a criança mais acessível, de certa forma facilita o trabalho da enfermagem também. Nem se compara você pegar uma criança que a mãe tá junto dizendo: "vamos filho!" E tal [...] e você pegar uma criança e dizer: "vem para tia". Não é a mesma 
coisa. Então, assim, eu vejo que a família é mediadora dessa relação equipe-criança (E4).

O fato de a família conhecer melhor e constituir-se como a fonte primária de relação de confiança da criança, a torna um elo entre a criança e o ambiente hospitalar como um todo. Assim, tornase importante a valorização da presença familiar pela enfermagem, e o seu reconhecimento como porto seguro da criança durante todo o período de hospitalização, período este que se constitui como um processo desconhecido e temeroso.

A mãe segurava sua filha tentando conter seus movimentos a fim de que a punção venosa fosse feita. A mãe, que já transparecia um semblante de aflição e inquietação, procurava manter-se calma ao ver sua filha ter sido furada pela terceira vez, sem sucesso. A mesma olhava e falava a todo instante com sua filha, tentando acalmá-la e acalentá-la, dizendo: "sim, meu amor, mamãe tá aqui, fique quietinha para terminar logo" (O8).

A enfermeira observou o gotejamento do soro e a permeabilidade do acesso venoso e, ao mesmo tempo, perguntou à criança se ela havia dormido bem e se já tinha urinado após a cirurgia. A menina não respondeu nada, mas olhava firmemente para a mãe. Nesse momento, a mãe se pronunciou e disse: "ela já fez xixi sim, mas não dormiu direito não!" (O1).

As situações observadas e relatadas acima demonstram que a família, como mediadora da criança no hospital, é a porta-voz das preocupações e sentimentos daqueles que acompanham, transmitindo à equipe os sinais e as mensagens enviadas pela criança e que não são percebidas pelos profissionais.

As enfermeiras salientam o fato de a família ser vista como um agente facilitador do trabalho da equipe de enfermagem na tarefa do cuidar. [...] a gente tem quase cem por cento de crianças acompanhadas. Então, não que a mãe seja recurso humano, mas não tem como, o acompanhante vai diminuir o trabalho da equipe, sempre [...]. Se ela for, no meu ponto de vista, a pessoa que tá aqui para dar carinho e atenção, já vai diminuir o trabalho da equipe, porque a aproximação vai ser mais fácil. Então, assim, a gente vai tá muito mais junto da criança e eu vejo tá junto como diminuição do trabalho, trabalho no sentido técnico (E4).

Tanto os depoimentos das enfermeiras quanto os registros de observação citados mostram o entendimento da importância que a enfermeira demonstra quanto à presença da mãe ou outro acompanhante significativo junto da criança, dando suporte emocional para a realização de procedimentos técnicos. Esse contexto mudou a relação de trabalho nas inter- nações pediátricas, pois até algum tempo atrás, registrava-se na literatura ${ }^{17}$ o sofrimento psíquico dos profissionais na realização de determinados procedimentos, que se agravava na ausência de familiares junto à criança.

\section{Cuidado prestado à criança pelas mães e equipe de enfermagem: relação assimétrica}

Percebemos que não há uma negociação entre as mães e as enfermeiras em relação aos cuidados a serem prestados à criança, durante seu período de hospitalização. Esta não tem sido uma tarefa fácil nem para as enfermeiras e demais componentes da equipe de enfermagem, que não têm claro seu papel nesse processo, nem para as mães, pois não sabem o que delas é esperado nas unidades de internação pediátrica. Assim, a enfermagem tem passado para a mãe cuidados que antes eram de sua responsabilidade:

Enfermeira: "mãe, e o banho?" Mãe: "eu dei o banho dele agora há pouco". Enfermeira: "conseguiu retirar o curativo?" Mãe: "consegui sim, tava bem sequinho!" A enfermeira pediu à criança para olhar a ferida, confirmando o que a mãe havia dito (O5).

Em relação às atividades realizadas pela mãe no hospital, as enfermeiras salientam que os cuidados mais simples ela pode, sim, fazer, se ela desejar (E4). No entanto, é importante além do desejo em realizar as ações de cuidado, que a mãe se sinta segura para essa tarefa.

Eu entendo dessa forma: se a família vai realizar, por exemplo, um banho, numa criança, que o estado geral tá bom, não tá com cateter, não tá com punção, eu não vejo razão para ela não dar, desde que ela se sinta segura, porque às vezes ela pode, como uma mãe que tá aqui, ela tem um bebê que não tem cateter nenhum, mas tem uma ascite enorme, com uma circulação colateral que, às vezes, você vê a hora romper, e, assim, a acompanhante não se sente segura em dar aquele banho, porque a pele dele pode até romper, entendeu? Eu acho que um banho pode ser simples para uma mãe e pode não ser para outra [...] (E4).

Ao não se estabelecer diálogo interativo com a mãe para tentar uma negociação nas ações de cuidado, esta acaba não sendo feita de modo claro, mas implicitamente. Os acordos não são abertamente discutidos, mas velados e como a mãe se sente responsável pela criança, vai assumindo determinados cuidados. ${ }^{18}$

A enfermeira perguntou à mãe se sua filha estava tolerando bem a dieta pela sonda enteral. A mãe disse que sim, que "tava dando tudo que vinha" e que de vez 
em quando molhava a boca da menina com água para os lábios não ressecarem (O9).

Esse tipo de cuidado realizado pela família, entretanto, foi apontado como algo que tem preocupado algumas enfermeiras do setor: [...] a mãe tinha ido buscar a seringa para dar a dieta, e a gente tem visto muito isso na prática. Alguns enfermeiros têm se preocupado com isso [pausa]: a família dando dieta por sonda. Isso é uma coisa que a gente tem discutido, totalmente despreparada, totalmente leiga, sem ter as mínimas condições, considerando-se a habilidade e conhecimento técnico de realizar (E4).

Embora explicitem a preocupação com esse fato, no cotidiano da assistência não foi observada nenhuma reflexão ou ação que possa contribuir para uma mudança identificada como necessária pelas enfermeiras.

Então, com quem a mãe vai aprender a fazer os cuidados que nem deveria estar fazendo? Com os outros acompanhantes. Por quê? Porque não teve aquela equipe para acolher, para conversar, para ver se aquela mãe tem condições para acompanhar. Porque quantas e quantas vezes já veio acompanhante sem condições emocionais, psíquicas mesmo, entendeu? (E4).

A família da criança se sente acolhida no hospital quando, no contexto relacional, percebe que as qualidades pessoais e profissionais daqueles que encontra ao longo de sua vivência, acomodam suas expectativas e proporcionam o estabelecimento de uma relação que lhe permita sentir-se segura para agir na situação. ${ }^{19}$

Muitos cuidados realizados pela família no hospital têm mostrado a permeabilidade do saber técnico ao não técnico, pois a família recria passos de procedimentos e saberes estruturados fazendo do seu modo, já que não recebe informações de como proceder. A prática assistencial tem evidenciado que a produção do cuidado à criança hospitalizada se reconstrói nesse processo. Entretanto, os resultados deste estudo apontam que, no hospital, as enfermeiras tem estabelecido uma relação assimétrica com a família e pautada pela desresponsabilização das profissionais no que tange a determinados cuidados de enfermagem. Tema que urge ser trazido ao debate.

\section{A percepção dos sentimentos da família na execução de procedimentos técnicos}

A hospitalização infantil é um evento que afeta a família como um todo. O sofrimento da família frente à hospitalização da criança e o sentimento das enfermeiras perante esse sofrimento é um dos aspectos que tem se mostrado relevante na relação enfermeira-família.

A gente tenta mostrar à mãe que a gente não está aqui para fazer, porque muitas pensam: "ah! estão aqui querendo furar, furar, furar!" Não! Porque para a gente seria muito melhor se na primeira vez a gente conseguisse [puncionar a veia] (E4).

Nesse sentido, algumas enfermeiras da equipe percebem o sentimento de angústia e dor da mãe, enquanto outras ainda não se mostram sensíveis.

A criança chorava e gritava a cada vez que a enfermeira tocava em seu corpo em busca de uma veia onde pudesse ser feita a punção. A mãe, em pé ao lado da maca, estava bastante emocionada. Seu rosto demonstrava dor pelo sofrimento do filho. A enfermeira olhou para a mãe e vendo seu sofrimento, disse: "a mãe sofre mais que o filho nessas horas". Olhou para a criança e disse: "chore não, rapaz! Dói um pouquinho, mas num instante passa" (O1).

Já era a terceira tentativa de punção venosa, sem sucesso. A mãe pediu para sair um pouco com a criança para acalmá-la, sem, no entanto, ser ouvida e atendida pela equipe. A enfermeira continuou a procurar outro local para fazer a punção [...] (O9).

Estudo $^{19}$ sobre a experiência de interação da família no hospital afirma que quando está imobilizada pelo sentimento de insegurança, a família deixa-se guiar pelas ações do profissional. Esse aspecto é corroborado neste estudo, pois, mesmo diante do seu esgotamento de possibilidade de continuar assistindo o sofrimento do filho, a mãe permaneceu na sala de punção tendo dificuldade em expressar sua necessidade.

É importante dialogar com a mãe quando a realização de alguma técnica dolorosa se faz necessária, procurando explicar-lhe como a mesma será feita, bem como a importância disto para a recuperação de seu filho, pois os procedimentos dolorosos realizados na criança hospitalizada são uma das principais fontes de sofrimento para a mãe. Acrescenta-se a isso o fato de que mesmo a mãe, reconhecendo o benefício de tais procedimentos para o tratamento da criança, sofre ao ver o sofrimento do filho. ${ }^{18}$

No cotidiano do hospital, o procedimento de realização de punção venosa é um dos que desencadeia maior sentimento de dor, tanto na criança como na mãe. Buscando minimizar o sofrimento da mãe, o diálogo tem sido uma da ferramenta importante. Já o sofrimento da criança tem sido enfrentado com uso da técnica do brin- 
quedo terapêutico. A literatura demonstra que a utilização desta técnica é um valioso instrumento no preparo de crianças para procedimentos, pois não só lhes permite extravasar seus sentimentos e compreender melhor a situação, como subsidia a equipe para a compreensão das necessidades da criança. ${ }^{20-22}$ Importa que ambos, família e criança, compreendam a importância da realização de um procedimento, mesmo que doloroso e desconfortável, para a recuperação da saúde. O depoimento a seguir demonstra a intenção da enfermeira em amenizar o sofrimento da mãe, procurando explicar-lhe a importância do procedimento para o tratamento da criança.

A gente, quando punciona, tem que tá conversando com a mãe, tem que tá orientando. Às vezes, a criança tá com um acesso difícil, um acesso na região frontal ou em alguma parte da cabeça, então, a gente tenta conversar, dizer a necessidade (E4).

Em nenhum momento foi observada a utilização, pelas enfermeiras, de técnicas para amenizar o sofrimento físico e psíquico da criança, apesar de sua importância para a saúde mental desta e da família no processo de hospitalização. Essa situação evidencia que ainda são muitos os desafios a serem superados para que o enfoque da assistência à criança hospitalizada passe daquele centrado em procedimentos para aquele centrado na criança e na família.

\section{CONSIDERAÇÕES FINAIS}

Na unidade em estudo as enfermeiras não tem envolvido a família no processo de cuidado à criança, interagindo com ela e instrumentalizandoa, a fim de que se torne coparticipante do processo saúde-doença do filho. Â família são delegadas, por vezes de modo implícito, tarefas, antes, de responsabilidade da enfermagem.

Assim, as relações estabelecidas pelas enfermeiras com a família não contemplam princípios de solidariedade, aproximação, empatia, estabelecimento de vínculos, responsabilizações e acolhimento. Atitudes dessa natureza poderiam contribuir para que a família se sentisse mais segura e fortalecida diante do processo de hospitalização de sua criança.

Apesar de a abordagem do cuidado centrado na díade criança-família preconizar ações humanísticas e interativas, neste estudo, a comunicação entre as enfermeiras e a família se mostrou do tipo vertical, formal, cabendo à enfermeira informar aquilo que julga necessário, não havendo um com- partilhamento de cuidados. A família tem assumido uma postura passiva, deixando-se guiar pelas ações dos profissionais, sentindo-se imobilizada para superar as limitações impostas pelo serviço. Mesmo que as enfermeiras demonstrem preocupação quanto à produção do cuidado à criança e sua família, não está havendo reflexo positivo em suas ações no cotidiano do trabalho.

$\mathrm{Na}$ hospitalização infantil o compartilhamento do cuidado é necessário, porém, a delegação de tarefas sem coparticipação e coresponsabilização não implica em melhoria da qualidade da assistência. A enfermeira que atua em pediatria precisa pautar suas ações de cuidado na interação dialógica com a família e a criança, apoiando, protegendo e fortalecendo o relacionamento com eles e entre eles durante a hospitalização.

Discussões desta natureza se tornam importantes no sentido de desencadear reflexões acerca das relações que as enfermeiras tem estabelecido com a família das crianças hospitalizadas, a fim de construirmos uma atenção à saúde dessa díade na perspectiva da integralidade do cuidado em saúde. Passados vinte anos do ECA e do ingresso formal da família no hospital, ainda não avançamos efetivamente na construção de um projeto terapêutico centrado na criança e sua família, que torne a família autônoma e copartícipe do cuidado no hospital.

\section{REFERÊNCIAS}

1. Ministério da Saúde (BR). Estatuto da Criança e do Adolescente. Brasília (DF): MS; 1991.

2. Andraus LMS, Oliveira LMAC, Minamisava R, Munari DB, Borges I. Ensinando e aprendendo: uma experiência com grupos de pais de crianças hospitalizadas. Rev Elet Enferm [online]. 2004 [acesso 2010 Fev 22]; 6(1):98-103. Disponível em: http://www. fen.ufg.br/revista/revista6_1/pdf/r2_pais.pdf.

3. Collet N, Rocha SMM. Criança hospitalizada: mãe e enfermagem compartilhando o cuidado. Rev Latinoam Enfermagem. 2004 Mar-Abr; 12(2):191-7.

4. Fernandes CNS, Andraus LMS, Munari DB. O aprendizado do cuidar da família da criança hospitalizada por meio de atividades grupais. Rev Eletr Enferm [online]. 2006 [acesso 2010 Fev 22]; 8(1):108-18. Disponível em: http:/ / www.fen.ufg. br/revista/revista8_1/original_14.htm.

5. Vernier ETN, Dall'Agnol CM. (Re)ações de uma equipe de enfermagem mediante a permanência conjunta em pediatria. Acta Paul Enferm. 2004 AbrJun; 17(2):172-80.

6. Yamamoto DM, Oliveira BRG, Viera CS, Collet N. O processo de trabalho dos enfermeiros em unidades de alojamento conjunto pediátrico de instituições 
hospitalares públicas de ensino do Paraná. Texto Contexto Enferm. 2009 Abr-Jun; 18(2):224-32.

7. Morais GSN, Costa SFG. Experiência existencial de mães de crianças hospitalizadas em unidade de terapia intensiva pediátrica. Rev Esc Enferm USP. 2009 Set; 43(3):639-46.

8. Gil AC. Como elaborar projetos de pesquisa. $4^{\mathrm{a}} \mathrm{ed}$. São Paulo (SP): Atlas; 2002.

9. Minayo MCS. O desafio do conhecimento: pesquisa qualitativa em saúde. $10^{\mathrm{a}}$ ed. São Paulo (SP): Hucitec; 2007.

10. Alves AM, Gonçalves CSF, Martins MA, Silva ST, Auwerter TC, Zagonel IPS. A efetividade do cuidado solidário diante de eventos que acompanham a cronificação da doença da criança hospitalizada. Rev Eletr Enferm [online]. 2006 [acesso 2010 Fev 22]; 8(2):192-204. Disponível em: http://www.fen.ufg. br/revista/revista8_2/v8n2a04.htm.

11. Sabatés AL, Borba RIH. As informações recebidas pelos pais durante a hospitalização do filho. Rev Latino-am Enfermagem. 2005 Nov-Dez; 13(6):968-73.

12. Barbosa ECV, Rodrigues BMRD. Humanização nas relações com a família: um desafio para a enfermagem em UTI pediátrica. Rev Acta Sci Health Sci. 2004 Jan-Jun; 26(1): 205-12.

13. Martins JJ, Nascimento ERP, Geremias CK, Schneider DG, Schweitzer G, Neto HM. O acolhimento à família na unidade de terapia intensiva: conhecimento de uma equipe multiprofissional. Rev Eletr Enferm 2008; 10(4):1091-101.

14. Almeida MCP. O trabalho de enfermagem e sua articulação com o processo de trabalho em saúde coletiva: rede básica de Ribeirão Preto [tese]. Ribeirão Preto (SP): Universidade de São Paulo, Escola de Enfermagem de Ribeirão Preto; 1991.

15. Lima RAG. Criança hospitalizada: a construção da assistência integral [tese]. Ribeirão Preto (SP):
Universidade de São Paulo, Escola de Enfermagem de Ribeirão Preto; 1998.

16. Deslandes S. Análise do discurso oficial sobre a humanização da assistência hospitalar. Ciênc Saúde Coletiva. 2004 Jan-Mar; 9(1):7-14.

17. Pagliari J, Collet N, Oliveira BRG, Viera CS. Sofrimento psíquico da equipe de enfermagem na assistência à criança hospitalizada. Rev Eletr Enferm [online]. 2008 [acesso $2010 \mathrm{Fev} 22$ ]; 10(1):63-76. Disponível em: http://www.fen.ufg.br/revista/ v10/n1/v10n1a06.htm.

18. Pinto JP, Barbosa VL. Vínculo materno-infantil e participação da mãe durante a realização da punção venosa: ótica da psicanálise. Rev Latino-am Enfermagem. 2007 Jan-Fev; 15(1):150-5.

19. Ribeiro PJ, Sabatés AL, Ribeiro CA. Utilização do brinquedo terapêutico, como um instrumento de intervenção de enfermagem, no preparo de crianças submetidas à coleta de sangue. Rev Esc Enferm. USP. 2001 Out-Dez; 35(4):420-8.

20. Silveira AO, Angelo MA. experiência de interação da família que vivencia a doença e hospitalização da criança. Rev Latino-am Enferm. 2006 Nov-Dez; 14(6):893-900.

21. Kiche MT, Almeida FA. Brinquedo terapêutico: estratégia de alívio da dor e tensão durante o curativo cirúrgico em crianças. Acta Paul Enferm. 2009 Mar-Abr; 22(2):125-30.

22. Leite TMC, Shimo AKK. Uso do brinquedo no hospital: o que os enfermeiros brasileiros estão estudando? Rev Esc Enferm USP. 2008 Abr-Jun; 42(2):389-95.

23. Nóbrega RD, Collet N, Gomes IP, Holanda ER, Araújo YB. Criança em idade escolar hospitalizada: significado da condição crônica. Texto Contexto Enferm. 2010 Jul-Set; 19(3):425-33. 